\title{
Correction to: Machine learning-based automatic reinforcing bar image analysis system in the internet of things
}

\author{
Jae Hwan Lee ${ }^{1} \cdot$ Sang Oh Park ${ }^{1}$
}

Published online: 5 July 2018

(C) Springer Science+Business Media, LLC, part of Springer Nature 2018

\section{Correction to: Multimed Tools Appl (2018) \\ https://doi.org/10.1007/s11042-018-5984-7}

In the original publication, the captured corresponding author was incorrect. The correct corresponding author is Sang Oh Park. The original article has been corrected.

Publisher's Note Springer Nature remains neutral with regard to jurisdictional claims in published maps and institutional affiliations.

The online version of the original article can be found at https://doi.org/10.1007/s11042-018-5984-7

Sang Oh Park

sopark@cau.ac.kr

Jae Hwan Lee

jhlee@cslab.cau.ac.kr

1 Chung-Ang University, 84 Heukseok-ro, Dongjak-gu, Seoul 06974, South Korea 